\title{
The Economic World Obverse: \\ Freedom through markets after arts education
}

\author{
Preprint $-7 / 19 / 2017$ \\ Alison Gerber \\ Uppsala University \\ Clayton Childress \\ University of Toronto
}

What role does arts education play in artistic activity and income? In light of the rise of university arts education and its effects, especially the changing role of teaching in artistic careers, this paper questions key assumptions of both winner-take-all and economic-worldreversed analyses of artistic careers. While almost all studies of remuneration in the creative arts find that income is highly skewed, these dominant perspectives take an object-oriented view of artistic life that neglects the vast majority of activities that underpin and compose contemporary arts practices. Looking at arts practices more holistically and using the changing status of art teaching as an exemplar of the expanded field of artistic practice, we document the challenges that the rise of arts education present to traditional analyses of artistic careers, income, and success.

\section{INTRODUCTION}

What role does arts education play in artistic activity and income? Research has suggested that artistic careers are bifurcated into two very dissimilar outcomes, in which a lucky few become "winners" and receive massive financial rewards while the vast majority earn minimal or no financial returns from their artistic practices (e.g. Abbing 2002; Menger 2014). Yet, given this situation, how do we make sense of the continued practices of the art market's myriad of financial "losers"? As Bourdieu (1993) argues, rather than having tried and failed at financial success, some artists deliberately eschew income in a display of their commitment to making art for its own sake. These artists are, in effect, competing in an economic world reversed in which the winners in status (in that world) make the least salable art. In this reframed state of affairs, one can either make art that is oriented toward the market or art that is oriented toward the esteem of other artists, but not both. We consider both of these narratives about artistic careers - winner- 
take-all and the economic-world-reversed - and show how just a slight shift in analysis demands a reexamination of both prevailing accounts.

Relying on archival data, field research, and interviews with visual artists and writers, we argue that these two theoretical orientations only hold when researchers take an object-centered view of artistic careers (Gerber and Childress 2017). This object-centered view, in which salable artistic objects like sculptures and book manuscripts are the only legitimate outcomes of artistic labor, neglects the vast majority of activities that underpin and compose contemporary arts practices. Instead, we argue, artists construct artistic careers and work to preserve artistic freedom in the process through strategic engagement and disengagement across multiple markets. In this paper, we consider the effects of the changing field of arts education, using an attendant reconceptualization of arts teaching across fine art worlds as just one example of the multiple markets across which artists negotiate careers today. In short, artists do not attain careers or fail to achieve them; rather, they strategically work across markets to make careers for themselves.

After positioning our study in the literature, we frame our analyses through a discussion of the rise and effects of tertiary (university-level) arts education in the United States. With data drawn from our studies of the literary and visual arts fields in the United States we argue that an object-oriented vision of artistic activity neglects the majority of contemporary artists and their careers in favor of a theoretical assumption which may no longer hold. We show how this structural change necessitates a re-examination of the theories of artistic lives that predate it. In the United States, structural and cultural changes in artistic careers and practice over recent decades allow for pathways to autonomy through market activity. In this paper, we focus especially on the role of teaching in artistic practice. We close with thoughts on the historical and 
geographic specificity of artistic careers and discuss the possibilities of a sociological theory of those careers that moves beyond this-or-that binarism.

\section{SUPERSTAR MARKETS, PSYCHIC GOODS, AND ARTS EDUCATION}

Career success in the arts is most often measured in terms of income, with analysts looking to narrowly defined careers and finding wide inequalities (Abbing 2002; Bille and Jensen 2016; Caves 2003; Menger 1999; Montgomery and Robinson 2003; Thompson 2008; Towse 1996). Sometimes called “winner-take-all” (Ertug et al. 2016, Frank and Cook 2010), “winner-takemost" (Thompson 2010), or "superstar" (Rosen 1981) markets, the economic returns on artistic objects tends to follow a Pareto distribution, in which "relatively small numbers of people earn enormous amounts of money and dominate the activities in which they engage" (Rosen 1981: 845). Theories vary as to why this is the case, with some looking to the qualities of artworks themselves (Adler 1985), and others to the role of prior reputations of creators on their future works (Ertug et al. 2016, Merton 1972). Others still find evidence of a bandwagon effect among consumers, even net of object and artist characteristics (Menger 2014, Salganik, Dodds, and Watts 2006; Salganik and Watts 2008). Yet in all of these lines of inquiry it is taken as an implicit assumption that, like actors in other markets, artists compete with each other for economic gain.

Some sociologists question the winner-take-all assumption, and instead posit that while some artists are competing for market success other artists are competing to make the "best" art, as defined within communities of artists. In this reframing, the financial "have-nots" lack artistically generated income because they are instead in search of something else. Rather than selling out to the market, these artists have an "interest in disinterestedness" when it comes to financial profit-making (Bourdieu 1993: 40). This "loser wins" approach relies on the belief 
that the market for art objects is polluting to artistic values, and instead it is the lack of sales which marks one's seriousness and legitimacy as an artist (Bourdieu 1993:169). In this formulation to "starve" for one's art is to have won the counter-game, and to play "loser wins" is to have a vested interest in making "pure, abstract, and esoteric" art which is of reputational and cultural value because it is not easily saleable (Bourdieu, 1993:120). This orientation among artists is, in Bourdieu's terminology, an "economic world reversed."

In some ways this argument is simply an elegant restatement of an economist's rational choice model: that, as Menger has put it, the possible income lost by artists "has been exchanged in return for psychic goods" (Menger 1999:556) as a means of dealing with a tensionfilled binary (Eikhof and Haunschild 2007). In this tradition, these psychic goods and the autonomous pole in which they are traded are in need of exploration (eg. Bille et al. 2013; Dubois and François 2013). This vision of "pure" art versus a "polluting" but financially remunerative market for the arts is also widely held outside of the academy, and continues to find expression in texts circulated in arts communities (eg. the recent re-emergence of The Gift (Hyde 1983) in high fine art circles). Quite tidily, were these economic-world-reversed assumptions to hold, they could partially explain the long tail of small economic returns in the winner-take-all research stream: many people in the long tail do not making money from their art because they are actively invested in not making money from their art. For authors in the economic-worldreversed tradition, survey data on artists' income (from artistic objects) may produce misplaced worry among winner-take-all adherents.

Regardless of the proffered reason for why artistic income derived from sales is highly skewed, arts activists and the popular media have taken the fact of it to argue that artistic education does not offer rewards commensurate with its often high costs (Jahoda et al. 2014; Lam 2014). But recent research has suggested that obtaining an arts degree and pursuing a career in 
the arts is not nearly as dour a proposition as is often assumed (Childress and Gerber 2015; Frenette and Tepper 2016). When looking to more broadly defined outcomes, few artists actually live in the garret of our imaginations (Strategic National Arts Alumni Project 2011; Throsby and Hollister 2003; Throsby 2007).

Although some empirical work embraces artistic careers constructed of diverse activities (e.g. Craig and Dubois 2010; Janssen 1998; Karttunen 1998; Rosenstein 2004), analysts focused on arts education have tended to more regularly rely on available statistics and the theoretical baggage that may come with them. As Rosenstein points out, many studies of arts education and outcomes struggle "to construct research definitions that resonate with socially and culturally salient understandings of who artists are and what they do" (2004:60). As a result, some survey measurements of artistic income may be dangerously out of touch with contemporary artistic practice by inadvertently defining paid work (e.g. teaching) as forms of "self-subsidization" that hinder or overtake "real" artistic careers (e.g. Karttunen 1998). As the notion that all painters do is paint or all writers do is write has always been a fiction, that artists tend to live and work outside the boundaries of narrow, object-oriented outcome variables is well documented (Lena and Lindemann 2014; Menger 2001). As a result, restricting our understanding of the creative arts to a series of artistic acts and direct cash transfers through the objects produced from those acts may inadvertently bracket out the vast majority of artistic lives and incomes.

In lieu of taking an object-centered view of artistic activity and income, we instead follow authors such as Lindemann (2013) in questioning winner-take-all market assumptions, and build on the work of analysts who look to artists' own understandings of the boundaries of their artistic practices. We do so because the traditional and narrow object-centered view ignores both all activity carried out by artists that is not expressly the making of salable art (i.e. most of artistic 
practice) and all income generated from being an artist that falls outside the purview of the sale of objects (i.e. most artistic income for most artists). Through the analysis of artistic activities beyond the production of objects-for-sale, we highlight a blind spot of winner-take-all analyses. In turn, we reconsider world-reversed theories: in practice, even artists who make less salable objects may not eschew remuneration or remunerative motives, or be conflicted about drawing an income from their practices. As Oakley (2009) has suggested, “The importance of 'being an artist' lies not in its anti-commercialism, but in its assertion of meaning beyond the commercial" (282). This meaning, we argue, is drawn from a number of sources as artists strategically navigate across multiple markets in the construction of their practices and careers.

More generally our perspective is in broader allegiance with the Zelizerian tradition, which rejects "hostile-worlds" arguments and, instead, highlights the often conflict-free coexistence of economic life with other spheres, including the moral, aesthetic, and professional (for an overview see Zelizer 2011). Economic sociology departs from economics by looking closely to the actual workings of economic life as social life. We follow authors in this tradition who look to the arts in order to ask whether and how artistic autonomy interacts with markets (e.g. Velthuis 2005; Wherry 2006). We also see our position as being in step with more recent sociological theorizing across a wide swath of literatures which has moved to the consideration of continuities and blended logics and away from this-or-that binarization (e.g. Boltanski and Thévenot 2006; Lamont 2009, Mears 2011; Stark 2009, Kersten and Verboord 2014). In turn, the deliberative strategies we discuss - artists' visions of legitimate, autonomous practice underpinned by stable teaching work, and the strategic navigation to balance income and autonomy across multiple markets for artistic expertise and activity - fall in line with the more recent developments in field theory which provides more allowances for both deliberative 
cognition and strategic action (Childress 2017; Fligstein and McAdam 2012; Gerber 2017;

Leschziner 2015, Leschziner and Green 2013; Lizardo 2012; Lizardo and Strand 2009).

Rather than being slaves to a highly bifurcated market or maintaining autonomy by keeping one's distance from the market, as we show, artists in the modern United States work to create autonomy through market activities. We explore here one way that they have been enabled in doing so: the rise of post-secondary arts education in the United States. By looking to the ways that artists themselves experience and narrate their careers, we argue for an image of an economic world obverse: artistic work involves a multitude of roles and activities that can, for many, be seen as complimentary, mutually constitutive activities that collectively make up a holistic and rewarding artistic career.

\section{BACKGROUND: THE RISE OF ARTS EDUCATION}

The growth of tertiary and graduate arts education in the United States has been dramatic. Today, the vast majority of the 568 accredited MFA programs in the fine or literary arts in the United States were founded in the last thirty years or so, and over half of all MFA programs in creative writing in the country have been founded since the year 2000 (National Association of Schools of Art and Design 2016; Poets \& Writers 2016). This dramatic shift is widely discussed and well understood in the humanities (cf. Elkins 2009; Harbach 2014), but has been relatively underconsidered in social scientific studies of the arts, creative industries, and artistic careers. Instead, now deeply entrenched in what McGurl (2009) refers to as "the program era" of American arts and letters, much research and reporting on the arts in the United States has focused on the experiences and outcomes of students in these programs (Frenette and Tepper 2016; Jahoda et al. 2014; Lam 2014; Lena and Lindemann 2014, Pink 2004). 
Less well understood in the social sciences is the accompanying rise in teaching positions in these programs, and the effect of this growth on the artistic careers of practicing artists (Anderson and Risner 2013). As advanced degree programs in the arts still rely on smallgroup "crit" and "workshop" teaching methods, the ratio of teachers to pupils in most arts courses remains (intentionally) low. As a result, increasing enrollment today in arts courses necessitates a tightly linked increase in the number of paid instructors. Today, across all levels of education, a statistical majority of arts alumni have worked at least part time as arts educators in their careers (Frenette and Tepper 2016). As seen in Table 1, 59\% of professional writers and $66 \%$ of professional visual artists either have taught or currently teach. ${ }^{1}$ What's more, as professional standing increases, engagement in teaching work also increases, which may suggest that access to and the embrace of teaching opportunities allows for a higher likelihood of continued professional standing, or at least is associative with that standing. In total the impact of the growth of arts education on the income of working artists and their ability to maintain artistic careers has been pronounced. It is for this reason that Harbach has argued that "the university now rivals, if it hasn't surpassed, New York as the economic center of the literary fiction world"; the same can be said for the visual arts (2014:12; emphasis added).

Table 1:

Engagement in Teaching Work by Status as a Professional Artist, by Major

\begin{tabular}{lccc}
\hline \hline Major & $\begin{array}{c}\text { All arts } \\
\text { graduates }\end{array}$ & $\begin{array}{c}\text { Current and former } \\
\text { professional artists }\end{array}$ & $\begin{array}{c}\text { Current } \\
\text { professional artists }\end{array}$ \\
\hline Writing & $44.6 \%$ & $56.6 \%$ & $59.1 \%$ \\
Visual Arts & $58.6 \%$ & $64.4 \%$ & $65.6 \%$ \\
Dance & $82.4 \%$ & $90 \%$ & $92.1 \%$ \\
Music Performance & $82.1 \%$ & $88.7 \%$ & $90.6 \%$ \\
Theater & $56.7 \%$ & $62.9 \%$ & $65.9 \%$ \\
\multicolumn{1}{c}{$\mathrm{N}$} & & & \\
\hline
\end{tabular}

Source: Strategic National Arts Alumni Project, Waves 2011, 2012, 2013. 
In this article we consider the market for teaching as just one exemplar of labor markets that are open to artists as artists. Other occupations that have undergone related processes of symbolic embrace by artists but are not considered here at length include arts administration, nonprofit, and commercial work (cf. Gerber 2017). Below, we discuss the ways that teaching work has been reconfigured by artists as a legitimate element of artistic careers rather than as the kinds of "second jobs" or "day jobs" that should be bracketed away from artistic practice. As shown by Rabkin (2013), most artists who teach find their teaching work to be deeply intertwined with their formal art making, rather than being distant from their other artistic activities or just a way to make rent. We argue that artists work in different ways across multiple markets -with teaching being a primary one of those markets - to find freedom and autonomy in their artistic practice while generating income from their artistic activities.

\section{METHODS}

We draw on two case studies of contemporary artistic practice in the United States, focusing on the visual and literary arts. These two fields are particularly useful for our discussion as they were also the focus of Bourdieu (1993), the central theorist of the economic world reversed. Data on the literary field were collected over 18 months between 2008 and 2010, consisting of openended interviews with over 100 publishing professionals, consisting of working novelists, agents, editors, and sundry interlocutors working in and around the book trade. Interviews lasted between 30 and 90 minutes, and were coded for themes in Nvivo. Codes relevant to our analysis in this work included topical discussions of "money," "MFA" programs, "inspiration," and "career." A six-month organizational ethnography of a publishing house specializing in "literary" fiction and non-fiction was also conducted, in addition to participant observational field research at 
publishing fairs and festivals, author readings, workshops, and literary events. Fieldwork was conducted on the east and west coasts of the United States. Secondary sources include archival research in industry trade publications (e.g. Publishers Weekly) as well as the popular press.

Data on the visual arts field comes from a study using 80 semistructured in-depth interviews with visual artists and ethnographic fieldwork in four regionally defined art communities carried out in the United States between 2011 and 2013. "Visual artists" were defined for this project as individuals who have publicly exhibited visual artworks (drawing, painting, sculpture, photographs, and other forms commonly shown in institutions like museums of contemporary art) in the year prior to the interview. Taped semistructured interviews lasted on average 1.75 hours each and were transcribed verbatim and in full and integrated with fieldnotes. Transcripts were coded by hand and in Atlas.ti in two waves of thematic coding; codes relevant to our analysis in this work included discussions of "primary identity", "goals and success", "definition of art", and "art practice and employment". In this paper, the primary source of data from both of the aforementioned studies is formal, semistructured interviews.

Secondary sources include archival research on artists' organizations (Art Workers Coalition and Working Artists and the Greater Economy) and a database of 911 oral histories with visual artists drawn from archives at the Smithsonian Archives of American Art (all transcribed interviews available from the archive). We draw in particular, in the limited historical analysis presented here, on two subsets of this database: first, artists born in the 1930s and interviewed during the 1960s and 70s ( $\mathrm{T}_{1}$ data); second, artists born after 1960 and interviewed after 2000 ( $\mathrm{T}_{2}$ data, which also includes all interview and documentary data collected discussed above). Although we do not go in depth on this dataset here, we do use our previous work on it to frame our findings in this paper (Childress 2017; Gerber 2017; Gerber and Childress 2017). 
Much of the below looks at the place of the higher education system in the United States in terms of artists' roles, careers, and incomes. Our data displays diversity along two important dimensions of arts education engagement: degrees granted and past or current employment in teaching. Our sample includes untrained artists, those with minimal training, and graduates of both low-status and high-status bachelor's and master's degree programs. Most of those in our sample have some experience teaching, at least casually, and others have years of work in community, elementary, secondary, or tertiary education. Those involved in college teaching range from occasional adjuncts at low-status bachelor's programs to the chairs of high-status MFA programs. This study was not designed for quantitative analysis, and does not pretend to approximate a statistically representative sample of all of the visual artists in the United States. ${ }^{2}$ In keeping with conventions in fields such as cultural economics as well as federal occupational classifications, we refer to practitioners of both the visual and literary arts in this paper as "artists". All artists referred to by first name only are pseudonyms and are drawn from our data, while notes on and quotes from artists and others referred to by first and last name are drawn from secondary source material.

As noted, we have drawn on studies of the visual and literary arts as these two fields are at the historical center of economic-world-reversed thinking. There are many similarities between these two fields that are relevant to this study, but some differences as well. Visual artists and writers' educational trajectories share many features, including (as discussed above) the centrality of the "workshop" (or "crit") model in graduate education that necessitates high faculty-to-student ratios. In both fields, neither the BA/BFA nor the MFA are necessities for practitioners - there is no bar to entry to either field - but in both cases these degrees are today common and widely understood as necessary for some high-status careers. An important distinction between these two fields involves residential clustering and community-building: 
visual artists often cluster residentially, take studio space in warehouse buildings populated by other artists, and attend gallery openings and other field-specific networking and communitybuilding events. Writers, by contrast, are much less likely to share workspaces or attend regular events, and the shift to "school" culture has provided a degree of creative community that writers of the past had to more actively work for and seek out (Childress 2017). These data are necessarily historically and nationally specific, and we do not aim to represent the fine arts as a whole. As noted in Table 1, however, while professional actors teach at the same rate as do visual artists $(66 \%)$, dancers and musicians engage in teaching at much higher rates than do either writers or visual artists. While we do not aim to hypothesize beyond our data, we suspect that our analyses of writers and visual artists may be conservative cases regarding the role of teaching work in professional artistic careers more broadly.

\section{DATA AND ANALYSIS}

Those who can't do...

The incorporation of teaching-for-pay as part of an artistic career has become legitimated over the past fifty years among "real", "serious" artists. This change is part of a broader cultural shift among artists, who over this time have reconceptualized their practices: no longer primarily the creators of objects, today artists comfortably provide services as well, and value their skills and time as well as the artistic outcomes of their labor (Gerber and Childress 2017). Here we use the term "teaching" to encompass all teaching in the arts - whether at the community, elementary, secondary, university, or graduate level. Teaching can be thought of as a particularly remunerative element of a broad portfolio career that includes professional and service work. 
The shift that legitimated teaching as a reasonably uncomplicated element of a portfolio career in the arts was spurred in part by the indirect pathways that state funding for the arts has taken in the United States, with the state "hiding" funding for the arts in institutions like schools and nonprofit exhibition spaces rather than granting artists directly. As we have discussed elsewhere, organizations like the NEA developed a deliberate strategy during the 1970s to provide artistic income to already-working artists under the alibi of institution-building (Childress 2017). This has led to a strong alternative market for artists' time and skills and contributed new wrinkles to the complex relationship between artistic autonomy and market activity. Artistic training in the United States has undergone a professionalization process that has included emphases on theoretical knowledge and credentials and a more general move to school culture (McGurl 2009, Singerman 1999). The still-increasing numbers of students in formal artistic training has resulted in a flowering of arts education as a legitimate career path for "real" artists, rather than the holding ground for "failed" artists that, according to our archival data, it was often assumed to be as recently as the 1960 s and 70s. These jobs are ways for artists to make a living as artists - not "day jobs" to be excluded from the analysis of artistic practice. As students, today's emerging artists have often been taught by artist-teachers whose reputations as serious artists are not drawn into question by the normalized income available to the professorate. ${ }^{3}$ Teaching positions are clearly no sign of artistic failure today, as the presence of renowned artistprofessors is now a marker of elite MFA programs.

To be sure, not all teaching positions are equivalent, and for some disciplines the professorate can be just another winner-take-all market that leaves overqualified and underpaid academics in its wake. As is the case across most disciplines, for artist-teachers part-time work in community and elementary education is often low-paid, precarious, and low-status, while tenured professorships can seem vanishingly rare. Yet in contrast to what we might expect from a 
researcher with a $\mathrm{PhD}$ in sociology or classics, the artists we spoke with rarely saw work in elementary and community education to be a sign of "failure." Instead, they found these types of part-time artistic employment to be accommodating of an artistic career and even rewarding on their own merits. As Lindemann and Tepper (2017) show, those working as arts educators report a high level of satisfaction with their opportunity to be creative within their job: $92 \%$ of those working in arts education (at all levels) report being at least "somewhat" satisfied, rivaling the $95 \%$ of those working as fine artists. ${ }^{4}$ As we discuss below, unlike most other educators in university settings, artists do not generally wrap their occupational identities around the professorship, and instead view teaching work as part of a broader portfolio career of artistic work. As a result, what for many academics would reasonably seem to be low-paid, precarious, and low-status teaching work can be, for artists, jobs that allow for flexibility, comparatively low time commitment, regular income, and meaningful work complimentary to one's own artmaking. In an example of the type of community work that may seem undesirable to some traditional academics, Jason, a fine artist who works across media, started teaching while he worked on his BFA. With others he started a community arts program, eventually training and managing other teachers. He remembered that as a "wonderful job", not only because he found that he enjoyed teaching but also because it was highly flexible and paid far more per hour than other work available to him. "For a college student, every other job is restricted to minimum wage; that's the most you can make. I was making thirty-five dollars an hour per student. So I didn't have to have a real job at that point; it supported me quite well, and I found out that I love teaching." For someone trying to make a living on this kind of work, the high hourly wage is not as appealing as it might at first appear; we spoke with artists who worked five or less hours per week teaching, and presumably many were not able to obtain more. But for artists who prioritize their artistic practice and feel that it requires an investment of time, looking for a high hourly 
wage at the expense of security or a steady income can make sense, and was a pattern seen in many interviews with artists.

At the time of our interview, Jason still taught in a community setting, and he both enjoys it and sees it as an investment in himself: "If they didn't pay me for it I'd still do it for free. I like it that much. I just consider it that I'm refining a skill set that I need." Jason loved teaching in part because he found the work meaningful and in line with his values, a pattern commonly seen among artists, though certainly not restricted to them (Gerber 2017; Rosso, Dekas, and Wrzesniewski 2010; Wrzesniewski and Dutton 2001). Other artists who found their way into community- and elementary-level teaching positions felt strongly about the value of their teaching work, and found that it enriched their artistic practice. Gregory, who taught what he called "underprivileged" kids in elementary schools for a time, looked back on the experience as a life-changing one that prompted him to reevaluate his life and his practice: "It was a very good experience, and I felt like a lot of good things happened because I got involved in this other very real situation."

The career path of Armando, a painter, clearly illustrates the sacrifices artists make to do work in line with their values. After Armando finished college he took a job with a health insurance company. "It was hands down the worst experience I've ever had in my life. I was so miserable. It was awful. It was awful. I made the most money I have ever made, but... I was only there for two and a half years, but in that time I realized that those companies are inherently evil." He quit, with no other job lined up, and went to an art fair where a local school was recruiting: "They needed an art teacher, there were openings for part-time art teachers. I wasn't certified, so I took like a twenty-five thousand dollar pay cut to teach art part-time in the local public school systems and it was... it was hard, but it was so much better... it was just more gratifying for me than participating in something that really is evil." He made the decision to always "work in the 
arts", and at the time of our interview he ran a private school with small classes, which he called "a luxurious way of teaching." He is primarily a painter, and the school he runs enables his artistic career in many ways, providing financial security and physical space that balances the intermittent windfalls represented by sales and residency awards.

When we met Jason, Gregory, and Armando, they had only taught in community and elementary education; we can't yet know the full arc of their careers. Whether they move "up" in the teaching world or not is, to them, irrelevant to their greater goals: like most artists they did not aim to be art teachers, but instead found teaching to be a legitimate element of a career in the arts, usually carried out in order to support the artist's "habit" (Gerber 2017) of artmaking. Luis, though, provides evidence that these kinds of teaching jobs are not as distinct from careers in higher education as we might assume. Luis, a printmaker, was first and foremost an artist and had been for decades; he also worked with a number of community organizations over the years, eventually founding and running an important regional arts organization, and taught art in the prison system. When we met he had recently started work at an art school, teaching BFA and MFA students in a new position that he had obtained quite suddenly: "The school where I'm teaching, I mean I lucked out... I don't have a masters' degree, and I didn't even study printmaking in school really, but I had a body of work", one built up through decades of work supported largely by teaching in neighborhood and community organizations. He was surprised by the offer: "I thought I was going for an interview, and I wasn't going for an interview. The head of the school was showing me around, he says, this is where you're going to work. So they basically just hired me. I didn't even put in a resume, I didn't do anything. He just hired me on the spot." Luis found later that his "name had come up" in a meeting, and the school's staff had gone to see some of his work in an exhibition. "He went and he saw them and he goes, I saw your prints and that was it, I wanted to have you over here." 
Artists today are likely to see teaching careers, especially in higher education settings, as ideal artistic careers, rather than second-best art-adjacent work. Henry, a sculptor in the Midwest, was an adjunct art professor and held a blue-collar day job - the sort of job that artists in the 1960s and 70s saw as compatible with artistic practice and the pose of the "art worker" (Bryan-Wilson 2009). But Henry loved teaching, and entirely rejected the "can’t do, teach" logic in favor of one that sees teaching as a mark of artistic success, and as a natural part of a sustainable career for a working artist. At time of interview Henry hoped to "drop the day job" soon to focus on his artistic practice by finding a tenured position: "I'd like to have a fulltime job teaching, and tenure, just get my summers off, it'd be spectacular." His lack of ambivalence about teaching is reflected in our interviews with other artists; many who do not have permanent teaching positions dream of them, and those with stable teaching positions rarely see such work as detrimental to, or in conflict with, their artistic practice.

Sophie, like many others, hoped to one day teach, and saw it as a mark of success rather than a fate to be avoided. Like others who attended elite MFA programs, she assumed that a teaching career was a natural step that followed success in the arts. As Sophie explained, she was only a few years out of graduate school, and wasn't ready to look for teaching work: "I would like to teach... I feel like maybe in five years I could find a teaching job but right now... they're like, "What's your exhibition history?"' John, a tenured professor, told us: "I always thought that maybe teaching one day would become part of what I do because I like that work. That kind of work is so energizing and rewarding in its own way. I just love that kind of constant learning, that way of interacting with students, this no-two-days-ever-alike kind of thing. I love all of that." For Sophie, a teaching position and the regularized income that would come with it was the brass ring, not the sign of failure it might have been for earlier generations. Perhaps even more evocative, rather than being a "failed artist" by being a teacher, Sophie felt she was not yet 
successful enough as an artist to be hired to teach. In turn, John - having already achieved that form of success -rejects the old notion of teaching stealing time from one's "own work".

\section{Teaching as artistic practice, teaching alongside artistic practice}

Some are less effusive about the benefits of teaching careers, but they shrug off any notion that their artistic practice is negatively impacted by their teaching work. Such was the case for a tenure-track novelist, Kelsey, when considering other occupations that would pay less and interfere more with her artistic practice. Kelsey noted quite simply that "working here [at the University] pays well enough, and leaves me plenty of time to write.” Alan, a visual artist working as an adjunct professor, echoed this sentiment: "I am getting paid a lot more for less hours... I don't know where else I could get that kind of hourly rate at the moment." Both Kelsey and Alan might be understood as the quintessential "art for art's sake" artists: Kelsey is a published novelist with some acclaim among critics and other authors but without many sales; Alan works within an elite, MFA-educated, coastal art scene and enjoys a measure of esteem among artists while barely drawing any income from gallery sales. Yet if we look only at the art objects they produce, we might think of them as unsuccessful in terms of income and, in their "autonomy," as emphatically rejecting the market. A more holistic view of their careers as artists, though, shows that they develop their autonomy as artists through a market - a labor market in higher education that was designed to minimally infringe on their time in the production of art (Childress 2017).

Amy, now chair of her university art department and an artist with significant recognition among artists and critics, was more eloquent than most when, with a matter-of-fact directness, she explained how central teaching has been to her artistic career. She always knew that teaching was the path most likely to afford her the artistic autonomy she hoped for: "I 
personally had no financial cush[ion]. I put myself through undergraduate school and I put myself through graduate school and I had no family support whatsoever. I grew up on welfare in this country... I had no capacity to be like, 'I'm just going to be an artist.' Like it just wasn't realistic." She laughed, and went on: "I wasn't willing to be a waitress or be a housekeeper or work in a factory when I knew that I could do something else that... teaching at a college level seemed to be the most-friendly to having a practice." Amy calls herself very "calculated." She went straight through college and then an MFA program, immediately applying for - and getting - her first teaching job. For artists like Amy, teaching allows for autonomy from the market for objects - through a market not only for her time but also for her artistic skills in a professional career.

When talking about their lives as artists, a majority of artist-teachers cited positive artistic effects of their teaching careers, and it is clear that for many artists today teaching is a crucial pathway to artistic autonomy and success. As Mallory, a fiction writer who was department chair of an MFA program at the time explained to us, she found a sense of community among other writers - her colleagues and students - in her MFA program that she suspected she would otherwise not have had. Working in an MFA program saves her from what could have otherwise been a fairly isolated life as an artist, and her students give her joy: “They're just discovering, they're just getting started. And once in a while some student writes something really wonderful that I'm very thrilled to be around and part of, which is cool." Through interactions with her students, she feels her own artistic practice is improved: "Very often when I've been really hammering on some point with students...in a workshop I'll walk away from it and think, 'that's myself I'm talking about. I'm the one who needs to hear this,' you know?" Mallory, like others, saw her teaching work as contributing directly to her artistic practice, rather than just financially subsidizing it. 
Many teaching artists explicitly advocate for teaching careers as promoting artistic autonomy, sometimes drawing on a widely shared lay version of the economic world reversed. Peter, a sculptor and adjunct professor, points directly to the autonomy he finds in teaching art: "I like the teaching because it's regular and - I'm not in control, but I am. I have bosses, but I kind of decide what we do from week to week, and I like that.” Domingo, a tenure-track sculptor, explicitly contrasts the constraints of the market for objects with the relative freedom of the market he has chosen: "If I started to make art for a gallery, let's say, then I would say well, what do they want? And then I start to think about what they want and I would start to make work about that, rather than just going to my studio and making art." He talked about the work he was making now, and told us, "I know this is never going to sell. And that's one of the reasons I want to teach; I know I can, now I know I can do it well, and I can make money that way to support my... my habit."

As evidenced by these artist-teachers, artists' possibilities in and experiences of work in arts education significantly complicate both winner-take-all and economic-worldreversed theories of artistic positions and careers. While winner-take-all findings hold for the sale of objects, the rise of tertiary education has created a growing "middle class" of practicing artists, who aim for and sometimes find in higher education work that - compared to the other jobs they might hold to make a similar level of income - does not take up much of their time and more often than not contributes to their creation of artistic objects. In turn, while economic-worldreversed theories posit that those who make generally less salable art have opted for reputational returns over making a living, for the artist-teacher this is not the case: they operate with open eyes in an "alternative" art market and are rarely unwilling to talk about their financial lives and financial motivations. Although while advocating for an economic-world-reversed position Bourdieu saw the patronage system as even more restrictive of artistic autonomy than the market, 
the patronage system he described - one described by Baxandall as only illusorily populated by benevolent collectors and patrons (Baxandall 1972) - is quite different from the one we see today, with state patronage functioning intentionally at arm's-length from artistic activity (Childress 2017; Larsen 2016). Unlike in previous eras, the "program era" of American arts and letters has created a market that indirectly compensates artists for their artistic practices while at the same time the arm's-length nature of the relationship allows them autonomy in those practices.

To be sure, not all artists who work as teachers find their teaching and art making to be mutually constitutive: "it's just a way to make money," as one novelist-teacher told us. Another younger novelist, David, who works in a tenure track position in an MFA program, lamented teaching as a means of support, saying that "It would be nice if we [as novelists] could go back to living from writing." Yet older artists we interviewed who remember artmaking before the explosion of tertiary education shrug off the nostalgia trap of David's lament: they remember the near-impossibility of making a living wage at art work while maintaining personal artistic autonomy prior to the growth of arts education.

None of this is to suggest that teaching jobs are perfect, or equally distributed in prestige or pay across artists. Instead, many artists who held teaching jobs (or hoped to soon attain them) recognized them simply as preferable to other jobs that were more demanding, allowed for less autonomy, or were at best art-adjacent or insufficiently noble. Among our artistteacher respondents we found nowhere near the same degree of self-exploitation (McRobbie 2002; Oakley 2009), sacrificial labor (Ross 2004), free labor to get one's foot in the door (Frenette 2013), or the long hours and blending of pleasure and obligation (Hesmondhalgh and Baker 2008, 2013) that have been found across most other creative markets for labor. For our respondents, the real challenge of maintaining "authentic" artistic careers and autonomy was 
making sure that they did not fall out of balance: the threat of an out-of-balance teaching career, in which one became "too comfortable" and only made art to maintain credentials, was in effect similar to the threat of the out-of-balance market-oriented career, in which one gave up autonomy to make salable art (Gerber 2017).

For our respondents the key to authentic artmaking was moderation across different markets and artistic spheres: teaching was simply the preferred occupation for enacting this moderation. One of our interlocutors provided a telling case when he explained why he chose to give up his tenured professorship and instead continue teaching on a much more contingent and lower paid contractual basis for the same department. While he continued to enjoy the teaching, he had found that the service components and general departmental expectations of his tenured professorship got too much in the way of his art. Rather than allow his artistic career to fall out of balance he decided that for his career (as an artist) he would be better off giving up the security of a permanent position to rebalance teaching as a smaller part of his occupational portfolio. Teaching (whether on a contract or on the tenure track) was, for our interlocutors, often superior to most other standardized work as it allowed for the incorporation of, and support for, a broader artistic practice. But there are other such careers that are equally invisible to the winner-take-all and economic-world-reversed analysts. Those who can't - or won't - teach are not bound to garret-living poverty or money-grubbing salesmanship. In the following section we briefly discuss several such cases as alternatives to the incorporation of teaching into an artistic career portfolio.

From objects to projects

Synnove, a painter who does not work as a teacher, spent some time supporting her art practice through direct and indirect governmental funding; this kind of temporary "contract" 
work is today common across art worlds (Relyea 2013). As she explained, "When I was wanting to extend myself as a painter, and also do a project - well, did I tell you about all the money? The state passed a percent for the arts. I wanted some of that money. So I was thinking of, 'Okay, projects, projects, what could I do?"” She clarified: "I wanted to be paid to paint. And I was. I got that time where I treated it like a job and, 'No, can't be at work, got to go paint today.' So it was a way to give myself time." Project work has become a normal element of the arts funding landscape. Henry, the sculptor discussed above who hopes to leave his day job, highlighted the availability of project funding when he explained why he had chosen to live in his small city rather than moving to the coasts: "The awesome thing about being in this town as an artist is the insane amount of money from fellowships and grants. It's not matched anywhere." When he talked about particular artworks, he often talked about their granting history, even suggesting that the difficult process of obtaining funding was key to their development and success: a particular work "had a long history. I had the idea, and then I applied for a project grant, and I didn't get it. But you got feedback from there, the jurors actually gave you written feedback, so I retooled it and really worked and pushed it." The next year, he won the grant, and produced a project that was more mature and thoroughly realized than his initial idea would have allowed.

Artists didn't only apply for project grants in order to produce their own work; they also found ways to exploit ever more specific CFPs to support themselves and their practices. Jay, a sculptor, said flatly: “I'm very grantable." He went on to describe a huge and extraordinarily savvy project he'd been working with for years, beginning with a small grant from a university: a "mobile studio, a series of demonstrations around the state. They paid me a half-time salary to work with students on the project." He'd figured out a way to extract capital resources from the project: "I actually used most of my salary to build the unit, so when I'd built 
the unit, at the end of the year it belonged to me, because I'd paid for everything." When we spoke he was in the middle of his tenth year working with, and drawing an income from, the project: that first year he drew no income, using it all to pay for the mobile studio, but the next nine it had been a moneymaker: 'I’ve never marketed it. They come to me, they'll see me demonstrating somewhere, and they'll call and say, 'we'd like you to come to our art museum and do a couple of days of demonstrations.' They provide the materials, I provide everything else. I do six demos a day and 75-100 kids per demo, 2 or 3 classes. So I can get 600 kids a day." He is, indeed, "very grantable," and through grants does financially remunerative artistic work that's deeply intertwined with his artmaking.

Even for artists apparently working entirely within the market for objects, the image of a winner-take-all or economic-world-reversed economy turns out to be more complex than we imagine. Such was the case for Maxine, a novelist who after obtaining an MFA in Creative Writing was resolute that she did not want to teach to support her art making. Instead, Maxine made about $70 \%$ of her living writing on contract for the African American imprint of a romance publisher. In her multi-market path to artistic autonomy, Maxine, however, had to also navigate the desires of her financers, which for her were sometimes less compatible with her beliefs and her "own" work. As she explained, when writing on contract for the romance publisher, characters and storylines were highly constrained: "Wealth is a requirement most of the time. No drug use, no cursing, the sex has to be romantic. It feels like they're trying so hard to be opposite to 'street lit.' It's like white romance fiction in black face, but with greater restrictions. It can feel like the policing of black sexuality."

Why did Maxine choose to write under such constraints? A look at her narration of this writing and her finances shows that she was strategically engaging across multiple markets for art as part of a broader artistic practice. Maxine was, in effect, treating her contract writing as 
a quasi-artistic form of wage labor, and using her income from that work to support her "own" writing in the less remunerative genre she preferred to work within. In this part of her practice, from which she generated the other $30 \%$ of her income, she had complete autonomy in her artmaking, and it was an autonomy she had "purchased" for herself through writing on contract. Although Maxine did not much like her contract writing or believe it to contribute to her actual art making, by doing work in one sector of the object-oriented market for art she was able to afford to live while freely practicing her art in a different sector of the object-oriented market.

For artist-teachers, artists getting by grant-to-grant, and artists who balance commercial and non-commercial work, artistic practice in the contemporary United States has important facets that are largely invisible in both winner-take-all and world-reversed accounts. Like artist-teachers, neither Synnove, Henry, nor Maxine are "winners" or "losers" in winnertake-all economies; rather, they fall somewhere in between. None of these artists clearly fall into an economic-world-reversed binarization of artistic practice, as across their practices they work to navigate both the physical need for income and the "psychic good" of unencumbered art making. While artist-teachers are the artists most at home in an economic world obverse, the relationship between income and artistic autonomy is more challenging for artists like Synnove and Maxine as they find themselves having to balance income and art-for-art's sake on an active and ongoing basis, keeping both sides of the market / autonomy coin in sight at all times. They both, however, do so, strategically making livings by finding pockets of money across different sources.

\section{DISCUSSION}

While in sociological theorizing and the popular imagination there is an inherent tension between practicing "art for art's sake" and making a living, the contemporary artistic economy in the 
United States can best be described as yet another reversal of this "economic world reversed": artists can maintain artistic autonomy while at the same time finding financial security through a wide-range of residencies, fellowships, and teaching positions in the arts. This arrangement of an economic world obverse has been developed through, enabled by, and professionalized via the contemporary system of arts education.

Our data, grounded in contemporary American artistic practice, complicates the images of artistic careers, autonomy, and success common to both the winner-take-all and economic-world-reversed research streams. We would be the first to caution that our findings are specific to a particular historical and national context: the applicability of our findings may not hold, for example, in contexts where narrower paths to occupations and professional careers mean that the value of an arts education or a career in teaching is viewed with more suspicion. Based on our findings, we would suggest that the degree to which an economic world reversed holds may be dependent on two factors: 1) state sponsorship of the arts through educational, employment, and tax policy, and 2) the degree to which marketized artistic practice can defend itself as "high", "privileged", "autonomous" art. We expect that, to varying extents, Western European state contexts today might allow for something that looks more like the autonomous pole described in Bourdieu, with their direct subsidies to artists allowing for artistic practice apparently at a distance from market activity wholesale. But the particularities of the American case brings renewed questions about the autonomous pole of artistic fields and to questions of autonomy and identity in professional and nonstandard work in general.

We suggest that our findings support further research across contexts along three lines. First, through the analysis of "alternative" markets - those for time and services, such as teaching - we can understand how income is secured by apparently "autonomous", avant-garde, and independent artists. Second, by looking to artists' practices and accounts, we can begin to 
disentangle the relationships between what appear to be distinct market and nonmarket activities. Finally, by orienting our gaze to precisely how artists navigate both artistic and financial concerns, we can learn more about artistic autonomy in diverse, complex, and highly unequal markets. Rather than being locked into positional and dispositional space (i.e. making art for art's sake or marketing art objects for sale) or fully controlled by highly unequal market forces (i.e. trying to get ahead in a single winner-take-all market), we argue that artists strategically navigate market fields; they neither reject the market nor fully embrace totalizing autonomy from it. Artists are calculative and agentic actors and use these abilities to find freedom through markets, rather than simply succumbing to or removing themselves entirely from the constraining forces of markets.

\section{CONCLUSION}

We have argued that analysts hoping to understand artistic careers should look beyond art objects to understand the diverse paths and income streams available to artists as artists. We have shown that in the contemporary United States not-for-profit institutions (here exemplified by education programs in the arts) have become the basis for legitimate career paths within the arts. This shift necessitates a reconsideration of the underlying assumptions of much of the literature on artistic careers, especially the emphasis on winner-take-all markets for objects, the assumptions of bifurcated cultural structures of purity and market activity within the arts, and the unnecessarily narrow view of legitimate artistic activity. Looking to primary and secondary market prices for art objects can illuminate many interesting questions; we simply argue that questions about the lives and incomes of the majority of artists are not among them.

The vast majority of artists in the US neither structure their lives around a winnertake-all market nor an economic-world-reversed; rather, they live in an economic world obverse, 
one where both sides of the coin are visible at all times and careers are made through purposeful and agentic movement through multiple markets. Without a vision of artistic activity beyond objects and an understanding of the effects of the development of arts education on these markets, analyses of the outcomes, benefits, and value of arts education will remain incomplete.

As the next generation of artists work their way through educational institutions in pursuit of artistically rewarding and financially viable careers, we close with a student-centered policy recommendation. In art schools, students are taught - both explicitly and implicitly many of the skills traditionally necessary for artistic careers. But art school culture, like social scientific analysis, has most often clung to an object-centered view of artistic practice, and left students ill equipped for the rich and diverse art worlds that await them. As teaching work, project-based work, grant writing, and other nonprofit work are now likely to be incorporated by even the most celebrated artists into portfolio careers - and today are part of standard artistic careers -the skills necessary for such work should, we believe, be offered as part of formal artistic training. If we can acknowledge that such work is a regular and normal feature of legitimate art careers, we might better prepare students to take advantage of opportunities open to them across art worlds, preparing the next generation of artists to successfully live and work as artists.

\footnotetext{
${ }^{1}$ These statistics draw on SNAAP data, discussed elsewhere in this issue. The question this data is drawn from was phrased as follows: "Have you ever worked as a full- or part-time teacher of the arts (i.e., classroom setting or private lessons)?"

${ }^{2}$ How to define the population of artists, and to what end, is a lively methodological debate among cultural policy and arts researchers (e.g. Karttunen 1998; Lena and Lindemann 2014; Menger 2001). While we have a relatively good sense of populations of artists with MFAs or who make most of their income from artistic practice (e.g. Brooks 2002; Bureau of Labor Statistics, U.S. Department of Labor 2011; Strategic National Arts Alumni Project 2011; Throsby 2010), this study derives from research projects that aim to include a broader diversity of artists. For
} 
detailed information on these projects, including sampling, interview schedules, coding, and other methodological issues, see (Childress 2017; Gerber 2015)

${ }^{3}$ Notable examples of celebrated artists who work in higher education might include Gregory Crewdson (Yale); Junot Diaz (MIT); Richard Ford (University of Mississippi); Andrea Fraser (UCLA); Glenn Ligon (Art Institute of Chicago); Colum McCann (Hunter College); Lorrie Moore (Vanderbilt); George Saunders (Syracuse University); Rirkrit Tiravanija (Columbia); and Kara Walker (Columbia).

${ }^{4}$ Professional fine artists do report being "very satisfied" at higher rates than art teachers $-78 \%$, vs. 56\% among all art teachers - but even if we only look to this high bar art teaching certainly performs well compared to other arts-adjacent work like arts administration (where only $30 \%$ report being "very satisfied"), working in galleries as a curator, dealer, or owner (35\%), or working as a graphic designer or illustrator (38\%). While artists value more than the ability to be creative at work, the widespread understanding that art teaching allows artists to flex creative muscles in their "day job" likely contributes both to the desirability of teaching work among those trained as artists as well as the sense that teaching jobs allow artists to earn money as artists.

\section{WORKS CITED}

Abbing, Hans. 2002. Why Are Artists Poor?: The Exceptional Economy of the Arts. Amsterdam: Amsterdam University Press.

Baxandall, Michael. 1972. Painting and Experience in Fifteenth Century Italy; a Primer in the Social History of Pictorial Style. Oxford: Clarendon Press.

Bille, Trine, Cecilie Bryld Fjællegaard, Bruno S. Frey, and Lasse Steiner. 2013. "Happiness in the artsInternational Evidence on Artists' Job Satisfaction." Economics Letters 121(1):15-18.

Bille, Trine and Søren Jensen. 2016. "Artistic Education Matters: Survival in the Arts Occupations." Journal of Cultural Economics 1-21.

Boltanski, Luc and Laurent Thévenot. 2006. On Justification: Economies of Worth. Princeton: Princeton University Press.

Bourdieu, Pierre. 1993. The Field of Cultural Production: Essays on Art and Literature. Cambridge, England: Polity Press.

Brooks, Arthur C. 2002. "Artists as Amateurs and Volunteers." Nonprofit Management \& Leadership 13(1):5.

Bryan-Wilson, Julia. 2009. Art Workers: Radical Practice in the Vietnam War Era. Berkeley and Los Angeles: University of California Press.

Bureau of Labor Statistics, U.S. Department of Labor. 2011. Occupational Outlook Handbook, 2010-11 Edition. 
Caves, Richard E. 2003. "Contracts between Art and Commerce." The Journal of Economic Perspectives 17(2):73-84.

Childress, Clayton. 2017. Under the Cover: The Creation, Production, and Reception of a Novel. Princeton: Princeton University Press.

Childress, Clayton and Alison Gerber. 2015. "The MFA in Creative Writing: The Uses of a 'Useless' Credential." Professions and Professionalism 5(2). Retrieved August 26, 2015.

Dubois, Sébastien and Pierre François. 2013. "Career Paths and Hierarchies in the Pure Pole of the Literary Field: The Case of Contemporary Poetry." Poetics 41(5):501-23.

Eikhof, Doris Ruth and Axel Haunschild. 2007. "For Art's Sake! Artistic and Economic Logics in Creative Production." Journal of Organizational Behavior 28(5):523-38.

Elkins, James. 2009. Artists with PhDs: On the New Doctoral Degree in Studio Art. Washington, DC: New Academia Publishing.

Ertug, Gokhan, Tamar Yogev, Yonghoon G. Lee, and Peter Hedström. 2016. "The Art of Representation: How Audience-Specific Reputations Affect Success in the Contemporary Art Field." Academy of Management Journal 59(1):113-34.

Frenette, Alexandre. 2013. "Making the Intern Economy: Role and Career Challenges of the Music Industry Intern." Work and Occupations 40(4):364-97.

Frenette, Alexandre and Steven J. Tepper. 2016. "What Difference Does It Make? Assessing the Effects of Arts-Based Training on Career Pathways." Pp. 83-102 in Higher Education and the Creative Economy: Beyond the campus, edited by R. Comunian and A. Gilmore. Abingdon, Oxon ; New York, NY: Routledge.

Gerber, Alison. 2015. "Art Work? Tradition, Rationalization, and the Valuation of Contemporary Artistic Practice." Yale University.

Gerber, Alison. 2017. The Work of Art: Value in Creative Careers. Palo Alto: Stanford University Press.

Gerber, Alison and Clayton Childress. 2017. "I Don't Make Objects, I Make Projects: Selling Things and Selling Selves in Contemporary Artmaking." Cultural Sociology.

Harbach, Chad, ed. 2014. MFA vs NYC: The Two Cultures of American Fiction. New York: Farrar, Straus and Giroux.

Hesmondhalgh, David and Sarah Baker. 2008. "Creative Work and Emotional Labour in the Television Industry." Theory, Culture \& Society 25(7-8):97-118.

Hesmondhalgh, David and Sarah Baker. 2013. Creative Labour: Media Work in Three Cultural Industries. Routledge.

Hyde, Lewis. 1983. The Gift: Imagination and the Erotic Life of Property. 1st Vintage Books ed edition. New York: Vintage. 
Jahoda, Susan, Blair Murphy, Vicky Virgin, and Caroline Woolard. 2014. Artists Report Back: A National Study on the Lives of Arts Graduates and Working Artists. BFAMFAPhD. Retrieved (http://bfamfaphd.com/wp-content/uploads/2016/05/BFAMFAPhD_ArtistsReportBack201410.pdf).

Karttunen, Sari. 1998. "How to Identify Artists? Defining the Population for [']status-of-the-Artist' Studies." Poetics 26(1):1-19.

Kersten, Annemarie, and Marc Verboord. 2014. " Dimensions of Conventionality and Innovation in Film: The Cultural Classification of Blockbusters, Award Winners, and Critics' Favourites." Cultural Sociology 8(1): 3-24.

Lam, Bourree. 2014. "M.F.A.s: An Increasingly Popular, Increasingly Bad Financial Decision." The Atlantic, December 19. Retrieved March 29, 2016.

Lamont, Michèle. 2009. How Professors Think. Cambridge, MA: Harvard University Press.

Larsen, Håkon. 2016. Performing Legitimacy: Studies in High Culture and the Public Sphere. Springer.

Lena, Jennifer C. and Danielle J. Lindemann. 2014. "Who Is an Artist? New Data for an Old Question." Poetics. Retrieved March 3, 2014.

Lindemann, Danielle J. 2013. "What Happens to Artistic Aspirants Who Do Not "Succeed"? A Research Note From the Strategic National Arts Alumni Project." Work and Occupations 40(4):465-80.

Lindemann, Danielle J. and Steven J. Tepper. 2017. "I Don't Take My Tuba to Work at Microsoft": Arts Graduates and the Portability of Creative Identity. American Behavioral Scientist.

McRobbie, Angela. 2002. "Clubs to Companies: Notes on the Decline of Political Culture in Speeded up Creative Worlds." Cultural Studies 16(4):516-31.

Mears, Ashley. 2011. Pricing Beauty: The Making of a Fashion Model. Berkeley, Calif. ; London: University of California Press.

Menger, Pierre-Michel. 1999. "Artistic Labor Markets and Careers." Annual Review of Sociology 25:54174.

Menger, Pierre-Michel. 2001. "Artists as Workers: Theoretical and Methodological Challenges." Poetics 28(4):241-54.

Menger, Pierre-Michel. 2014. The Economics of Creativity: Art and Achievement under Uncertainty. Cambridge, Massachusetts: Harvard University Press.

Montgomery, Sarah S. and Michael D. Robinson. 2003. "What Becomes of Undergraduate Dance Majors?" Journal of Cultural Economics 27(1):57-71.

National Association of Schools of Art and Design. 2016. Getting Your Bearings: An Introduction to NASAD. Reston, VA: National Office, NASAD. 
Oakley, Kate. 2009. "From Bohemia to Britart - Art Students over 50 Years." Cultural Trends 18(4):28194.

Relyea, Lane. 2013. Your Everyday Art World. Cambridge, MA: The MIT Press.

Rosenstein, Carole. 2004. "Conceiving Artistic Work in the Formation of Artist Policy: Thinking Beyond Disinterest and Autonomy." Journal of Arts Management, Law, and Society 34(1):59-77.

Ross, Andrew. 2004. No Collar: The Humane Workplace And Its Hidden Costs. Philadelphia, Pa: Temple University Press.

Rosso, Brent D., Kathryn H. Dekas, and Amy Wrzesniewski. 2010. "On the Meaning of Work: A Theoretical Integration and Review." Research in Organizational Behavior 30:91-127.

Singerman, Howard. 1999. Art Subjects: Making Artists in the American University. Berkeley: University of California Press.

Stark, David. 2009. The Sense of Dissonance: Accounts of Worth in Economic Life. Princeton: Princeton University Press.

Strategic National Arts Alumni Project. 2011. Forks in the Road: The Many Paths of Arts Alumni: 2010 Findings. Center for Postsecondary Research, School of Education, Indiana University.

Thompson, Donald N. 2008. The \$12 Million Stuffed Shark: The Curious Economics of Contemporary Art. 1st Palgrave Macmillan ed. New York, NY: Palgrave Macmillan.

Throsby, David. 2007. "Preferred Work Patterns of Creative Artists." Journal of Economics \& Finance 31(3):395-402.

Throsby, David. 2010. "Economic Analysis of Artists' Behaviour: Some Current Issues." Revue D'économie Politique 120(1). Retrieved September 22, 2011

Towse, Ruth. 1996. "Economics of Training Artists." P. 381 in Economics of the Arts, Contributions to economic analysis, edited by V. Ginsburgh and P.-M. Menger. New York: Elsevier.

Velthuis, Olav. 2005. Talking Prices: Symbolic Meanings of Prices on the Market for Contemporary Art. Princeton: Princeton University Press.

Wherry, Frederick F. 2006. "The Social Sources of Authenticity in Global Handicraft Markets Evidence from Northern Thailand." Journal of Consumer Culture 6(1):5-32.

Wrzesniewski, Amy and Jane E. Dutton. 2001. "Crafting a Job: Revisioning Employees as Active Crafters of Their Work." The Academy of Management Review 26(2):179-201.

Zelizer, Viviana A.Rotman. 2011. Economic Lives: How Culture Shapes the Economy. Princeton: Princeton University Press. 